\title{
Respirable Crystalline Silica Exposure among Concrete Finishing Workers at Apartment Complex Construction Sites
}

\author{
Hyunhee Park ${ }^{1,2}$, Eunsong Hwang1, Chungsik Yoon ${ }^{2 *}$ \\ ${ }^{1}$ Work Environment Research Bureau, Occupational Safety and Health Research Institute, Ulsan 44429, Korea \\ ${ }^{2}$ Department of Environmental Health Sciences, Institute of Health and Environment, Seoul National University Graduate \\ School of Public Health, Seoul 08826, Korea
}

\begin{abstract}
The objective of this study was to evaluate the level of exposure to respirable crystalline silica (RCS) among concrete finishers and to identify the size distribution of particles from concrete finishing work at apartment complex construction sites.

Active personal air sampling $(\mathrm{n}=129)$ was conducted at eight sites using filters with aluminum cyclones, and local air sampling for the size distribution of the particles $(n=6)$ was conducted using a Mylar substrate with cascade impactors. Crystalline silica was analyzed by Fourier-transform infrared spectroscopy (FT-IR). The collected personal samples were sorted by the type of task (concrete chipping, grinding, or plastering) for four kinds of working places (exterior walls, interior walls of apartment units, staircases, and underground parking lots).

The geometric mean (GM) of the RCS concentration was highest, although varying according to the type of structure, for concrete grinding $\left(2.06 \mathrm{mg} \mathrm{m}^{-3}\right)$, followed by chipping $\left(0.12 \mathrm{mg} \mathrm{m}^{-3}\right)$ and plastering $\left(0.003 \mathrm{mg} \mathrm{m}^{-3}\right)$. The maximum RCS concentration was measured in the staircases $\left(4.18 \mathrm{mg} \mathrm{m}^{-3}\right)$, followed by the interior walls of apartment units $\left(2.76 \mathrm{mg} \mathrm{m}^{-3}\right)$, underground parking lots $\left(1.30 \mathrm{mg} \mathrm{m}^{-3}\right)$, and exterior walls $\left(0.89 \mathrm{mg} \mathrm{m}^{-3}\right)$. The mass fraction of inhalable, thoracic, and respirable crystalline silica was respectively $73.9 \%, 40.2 \%$, and $17.9 \%$ in chipping and $76.0 \%, 46.3 \%$, and $19.7 \%$ in grinding.

Concrete finishing workers at apartment complex construction sites are exposed to unacceptably high concentrations of RCS. To protect workers' health, dust-minimizing construction methods as well as high-efficiency respirators paired with local exhaust ventilation systems or wet methods must be employed. Further efforts to reduce the total working time and to use full-faced air-purifying respirators are required.
\end{abstract}

Keywords: Construction workers; Concrete finishing; Respirable dust; Crystalline silica.

\section{INTRODUCTION}

Crystalline silica is a basic component of soil, sand, stones, and many other minerals that are the most frequently used materials at construction sites (Beaudry et al., 2013). The hazards of silica were recognized from tunnel excavation and mining in 1930, but recently have been broadly recognized in the construction industry (Sauvé, 2015). Most construction workers are exposed to respirable crystalline silica (RCS) by performing tasks that generate RCS or through diffused dusty air containing RCS (Flanagan et al., 2003; Sauvé et al., 2013; Oude et al., 2014). The tasks that generate large amounts of RCS at construction sites are concrete grinding, drilling, cutting and chipping, block and brick cutting, removing mortar between bricks, cutting rocks, and ballasting

\footnotetext{
* Corresponding author.

Tel.: 82-2-880-2734; Fax: 82-2-745-9104
}

E-mail address: csyoon@snu.ac.kr structures (Flanagan et al., 2003; Rappaport et al., 2003; Tjoe Nij et al., 2003; Sauvé et al., 2013; Oude et al., 2014). Many studies have reported that the concentration of RCS exceeded the occupational exposure limits in various construction jobs including concrete workers, such as recess millers, tuck pointers, and bricklayers; demolition workers; laborers; operating engineers; and even construction cleaners (Lumens and Spee, 2001; Rappaport et al., 2003; Tjoe Nij et al., 2003).

Crystalline silica is defined as a Group 1 carcinogen by the International Agency for Research on Cancer (IARC) (IARC, 2012) and has been associated with lung cancer, silicosis, kidney failure, and lung impairment. Silicosis has no standardized treatment method, so the most effective method is to minimize workers' exposure to prevent any related diseases (NIOSH, 2002). Surveys have indicated that there are about three million workers exposed to crystalline silica in the European Union (EU), 1.7 million in the United States, and 350,000 in Canada (Sauvé et al., 2013). In 
Britain, most workers exposed to silica are construction workers and over half of the lung cancer deaths in men in 2004 were attributable to work in the construction industry (Rushton et al., 2008).

Although some levels of silica exposure from construction activities have been reported, additional exposure assessment studies are needed because diverse environmental factors can affect the concentrations (Sauvé et al., 2013), as can the characteristics of the ever-changing construction site work environments (Akbar-Khanzadeh et al., 2002).

South Korea has a unique style of housing. That is, more than $60 \%$ of all houses are concrete apartments and apartment complexes, usually comprised of hundreds of households together in one area. In such a construction environment, large-scale concrete finishing work is carried out, but the levels of RCS exposure among concrete finishers have not been studied yet.

The objective of this study was to evaluate the exposure levels and size distribution of RCS among concrete finishers at the large-scale apartment complex construction sites.

\section{METHODS}

\section{Exposure Group Selection and Task Description}

Eight new apartment complex construction sites (Table 1) were selected to assess the concentration of respirable dust (RD) and RCS during concrete chipping, grinding, and plastering work between March and June in 2016. Concrete chipping (Fig. 1(a)) refers to using a hammer drill to cut off uneven concrete walls after removing the molding used to cure the concrete. Concrete grinding (Fig. 1(b)) is the use of a grinder to level a concrete surface after removing the molding. The grinder used for this study included a 4-in. industrial diamond wheel. Plastering work (Fig. 1(c)) involved mixing cement, sand, and water for application to the surface of concrete or brick walls to improve their aesthetic appearance.

A total of 36 workers participated in this study. They were examined for 3 consecutive days. Prior to each sampling, the workers were briefed on the purpose and method of sampling by our research staff and occupational health managers at their construction sites. Workers who volunteered for sampling wore RD and RCS samplers and informed consent was obtained verbally. We did not collect any personal information (name, gender, or age) when we received consent from the study participants. All participants in this study were adults. The research results are presented by mean, variance, and range according to job type.

To analyze the concentration of RD and RCS, 129 breathing zone personal samples (Table 1) were collected to represent each concrete finishing work hazard concentration. The samples were collected during work hours and several samples (up to 4 samples day ${ }^{-1}$ ) were collected from a single worker when processes changed during the day or the measured concentration was high. The sample collection times ranged from 55 to 523 minutes per sample. To identify the size distribution of crystalline silica, 6 cascade impactor samples were collected at Construction Site G during work hours for 2 consecutive days and the sample collection times ranged from 210 to 912 minutes per sample.

\section{Sampling and Analysis \\ Sampling}

Respirable dust was collected on gravimetrically analyzed polyvinyl chloride (PVC) filters (37-mm diameter, 5- $\mu \mathrm{m}$ pores; SKC, Inc., USA) mounted on an aluminum cyclone (SKC, Inc., USA) connected to a pump (Escort Elf Sampling Pump; MSA, USA) with a flow rate of $2.5 \mathrm{~L} \mathrm{~min}^{-1}$. The pumps were pre- and post-calibrated using a bubble calibrator (standard flow: $20 \mathrm{ccs}$ to $6 \mathrm{~L} \mathrm{~min}^{-1}$; Gillian Corp., USA).

\section{Gravimetric Analysis of Dust}

For the gravimetric analysis of dust, PVC filters were dried in a desiccator for over a day before sampling, stabilized in the gravimetric analysis chamber for $>2 \mathrm{~h}$, and weighed three times using an electronic balance with $10^{-7} \mathrm{~g}$ readability (XP2U; Mettler Toledo, Switzerland) to calculate the mean value. The samples and blanks were dried, weighed, and calculated same as pre-filters.

\section{Crystalline Silica Analysis}

Crystalline silica was analyzed using Fourier-transform infrared spectroscopy (FT-IR) in accordance with the NIOSH Manual of Analytical Methods (NMAM) of the U.S. National Institute of Occupational Safety and Health (NIOSH) \#7602 (NIOSH, 2003). To pre-treat the samples, the filter was placed in a jar and heated for $2 \mathrm{~h}$ in an electrical furnace set at $600^{\circ} \mathrm{C}$. Potassium bromide $(\mathrm{KBr} ; 300 \mathrm{mg})$ (FT-IR grade; Sigma-Aldrich) was added to the jar containing the filter ashes, mixed, and pressed in a $13-\mathrm{mm}$ pellet die to make pellets. FT-IR (FT/IR-4600; JASCO, Japan) was used to

Table 1. Target monitoring of working place and number of samples.

\begin{tabular}{|c|c|c|c|c|c|c|c|c|c|}
\hline \multirow{2}{*}{ No. } & \multirow{2}{*}{ Site } & \multirow{2}{*}{$\begin{array}{l}\text { No. of } \\
\text { households }\end{array}$} & \multirow{2}{*}{$\begin{array}{l}\text { Sampling } \\
\text { days }\end{array}$} & \multirow{2}{*}{$\begin{array}{l}\text { No. of } \\
\text { workers }\end{array}$} & \multirow{2}{*}{$\begin{array}{l}\text { Average sampling } \\
\text { time (min; (range) }\end{array}$} & \multicolumn{4}{|c|}{ No. of active personal samples (n) } \\
\hline & & & & & & Chipping & Grinding & Plastering & Sum \\
\hline 1 & A & 1,665 & 3 & 4 & $178(65-320)$ & 3 & 18 & - & 21 \\
\hline 2 & $\mathrm{~B}$ & 520 & 3 & 3 & $204(100-516)$ & 3 & 6 & - & 9 \\
\hline 3 & $\mathrm{C}$ & 1,103 & 3 & 3 & $250(151-298)$ & - & 2 & 3 & 5 \\
\hline 4 & $\mathrm{D}$ & 728 & 3 & 5 & $261(55-501)$ & 8 & 8 & 7 & 23 \\
\hline 5 & $\mathrm{E}$ & 761 & 3 & 3 & $267(160-480)$ & 10 & 2 & 3 & 15 \\
\hline 6 & $\mathrm{~F}$ & 995 & 3 & 9 & $319(61-523)$ & - & 8 & 16 & 24 \\
\hline 7 & $\mathrm{G}$ & 1,730 & 3 & 5 & $304(197-500)$ & 10 & 2 & 6 & 18 \\
\hline 8 & $\mathrm{H}$ & 450 & 3 & 4 & $279(201-486)$ & 2 & 12 & - & 14 \\
\hline Sum & & & & & & 36 & 58 & 35 & 129 \\
\hline
\end{tabular}


(a)

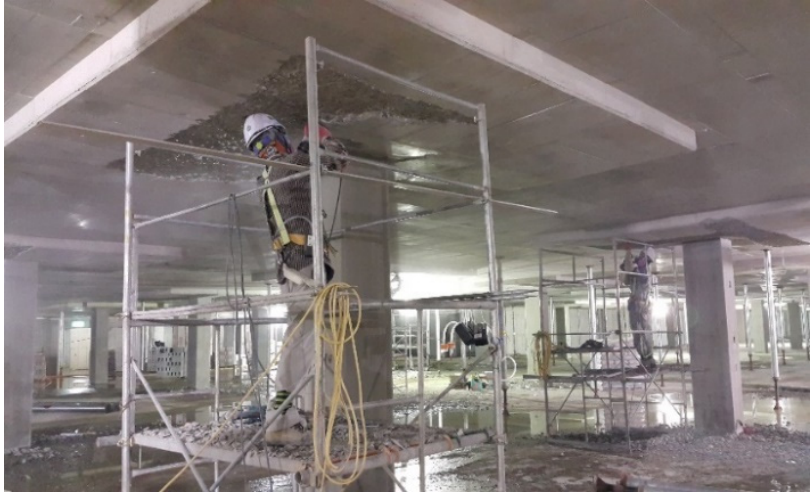

(b)

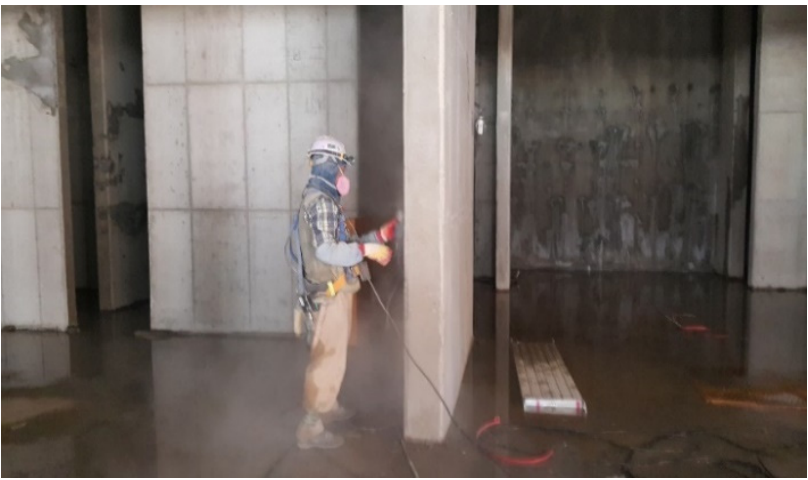

(c)

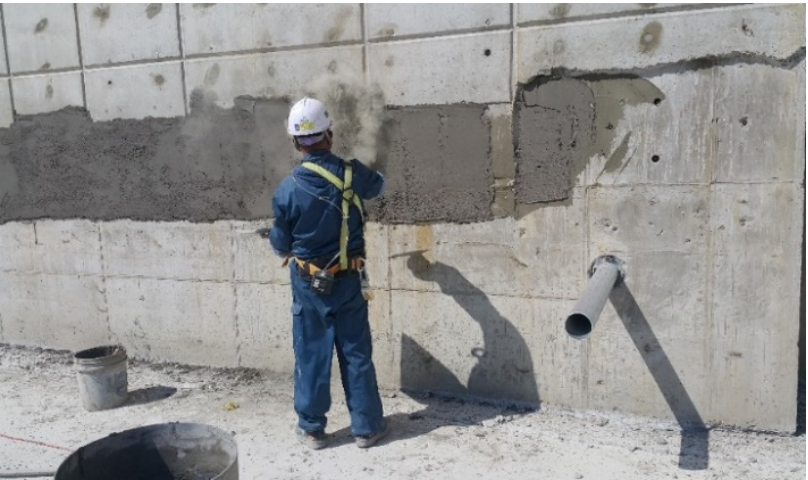

Fig. 1. Concrete (a) chipping, (b) grinding, and (c) plastering work.

measure the sample's absorbance at $600-900 \mathrm{~cm}^{-1}$ vibrations and the absorbance at $800 \mathrm{~cm}^{-1}$ vibrations was used to calculate the results. The calibration curve was created from 0.8 to $500 \mu \mathrm{g}$ using SRM1878a respirable alpha quartz from the National Institute of Standards and Technology (NIST) as the standard. If it was not possible to form pellets because there was too much dust or the amount of quartz exceeded the range of the calibration curve, a portion of the dust was separated to determine the ratio of the dust sample weight to the weight of the total amount of dust. The limit of detection (LOD) was $1.4882 \mu \mathrm{g}$ per sample. The amount of crystalline silica in all samples exceeded the LOD.

\section{Analysis of Particle Size Distribution}

In order to measure the size of dust, a Personal Cascade Impactor (Model 298; Andersen Samplers, Inc., USA) composed of an eight-stage impact plate was used. Mylar substrate (34-mm, 6-slot; TE-290-MY; Tisch Environmental, USA), the sample medium used to collect the dust particles, was coated with silicone lubricant (3M, USA) and dried before attaching it onto the eight-stage impact plate. This prevented the loss of dust particles by particle bounce (Vaughan, 1989). In the last stage, a PVC (5- $\mu \mathrm{m}$ pore size) filter was installed to even the flow of air. The flow was set at about $2 \mathrm{~L} \mathrm{~min}^{-1}$ to prevent particle bounce and loss from internal impacts at high flow and to prevent loss from internal accumulation at low flow.

The dust collected at each stage was assessed using gravimetric analysis and crystalline silica analysis. To calculate the mass median aerodynamic diameter (MMAD) of dust, the weight of dust from each stage was corrected by dividing it by the effectiveness suggested by the sampler manufacturer as the correction factor for the efficiency and internal loss of samples (Andersen Samplers, Inc., 1982). The corrected weight of dust was used to calculate the mass fraction (\%) of each stage (Tables S1-S2). To calculate the mass fraction of dust for each dust particle size, the American Conference of Governmental Industrial Hygienists (ACGIH) 
Particle Size-Selective Sampling Criteria for Airborne Particulate Matter was used (Bello et al., 2002). In this study, particle sizes were expressed as inhalable particulate matter (hazardous when deposited anywhere in the respiratory tract), thoracic particulate matter (hazardous when deposited anywhere within the lung airways and the gas-exchange region), and respirable particulate matter (hazardous when deposited in the gas-exchange region) (ACGIH, 2013).

\section{Statistical Analysis}

The results were tested for normality of resources to examine the characteristics of distribution using the ShapiroWilk test and the data showed a log-normal distribution except for the RD concentration during plastering. The geometric mean (GM) and geometric standard deviation (GSD) were used to explain the concentrations by job types and working places. ANOVA and Pearson correlation analysis with log-transformed data were conducted to compare the mean exposure concentration for each job type and each working place and to assess the relationship between respirable crystalline silica and respirable dust concentrations. Multiple linear regression analysis was performed to identify the exposure determinants affecting the RD and RCS levels. The variables included in the multiple regression model were types of jobs, working places, and sampling (working) time. The types of jobs and working places were nominal variables, so they were converted into dummy variables. Statistical analyses were performed using PASW version 18.0 (SPSS Inc.; Chicago, IL, USA). The figures in this study were generated using Sigma Plot version 13.5 (Systat Software, Inc.; San Jose, CA, USA).

\section{RESULTS AND DISCUSSION}

\section{RD and RCS in Concrete Finishing by Job Type}

The personal exposure to RD and RCS from concrete chipping, grinding, and plastering work at construction sites is shown in Table 2. The concentrations of RD and RCS were significantly different between job types $(p<0.001)$. The GM of RCS exposure from concrete grinding work was $2.06 \mathrm{mg} \mathrm{m}^{-3}\left(0.10-17.62 \mathrm{mg} \mathrm{m}^{-3}\right)$, which exceeded the Korean Occupational Exposure Limit (KOEL; $0.05 \mathrm{mg} \mathrm{m}^{-3}$, which is the same as the U.S. Occupational Safety and Health Administration's permissible exposure limits) by 41.2 times, based on an 8-hour work shift (Fig. 2). In addition, the GM of RCS exposure from concrete grinding work was more than 80 times the ACGIH threshold limit value (TLV) for crystalline silica $\left(0.025 \mathrm{mg} \mathrm{m}^{-3}\right)$. All samples exceeded the exposure limits of $0.05 \mathrm{mg} \mathrm{m}^{-3}$. The GM of RCS exposure from concrete chipping was $0.123 \mathrm{mg} \mathrm{m}^{-3}$ $\left(0.005-3.06 \mathrm{mg} \mathrm{m}^{-3}\right)$ and $75 \%$ of the samples $(27 / 36)$ exceeded $0.05 \mathrm{mg} \mathrm{m}^{-3}$. The GM of RCS exposure from plastering work was $0.003 \mathrm{mg} \mathrm{m}^{-3}$ (ND to $0.027 \mathrm{mg} \mathrm{m}^{-3}$ ) and no sample exceeded $0.05 \mathrm{mg} \mathrm{m}^{-3}$. The GM of RD exposure from concrete grinding was $49.96 \mathrm{mg} \mathrm{m}^{-3}$ (4.26$367.58 \mathrm{mg} \mathrm{m}^{-3}$ ), which exceeded the ACGIH's TLV for general dust (respirable particles not otherwise specified) of $3 \mathrm{mg} \mathrm{m}^{-3}$ by about 16.6 times. The exposure to concrete chipping workers was $1.78 \mathrm{mg} \mathrm{m}^{-3}\left(0.19-62.72 \mathrm{mg} \mathrm{m}^{-3}\right)$ and

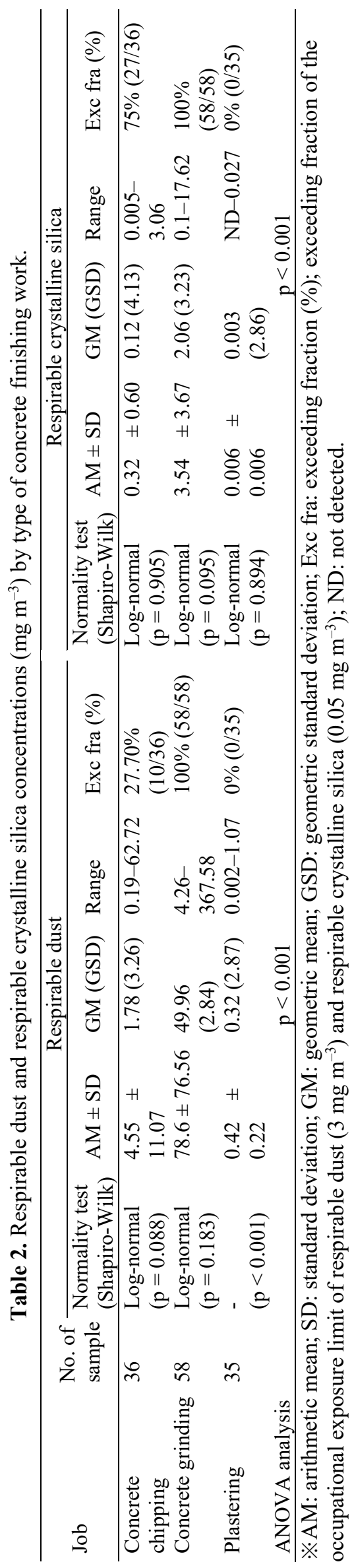




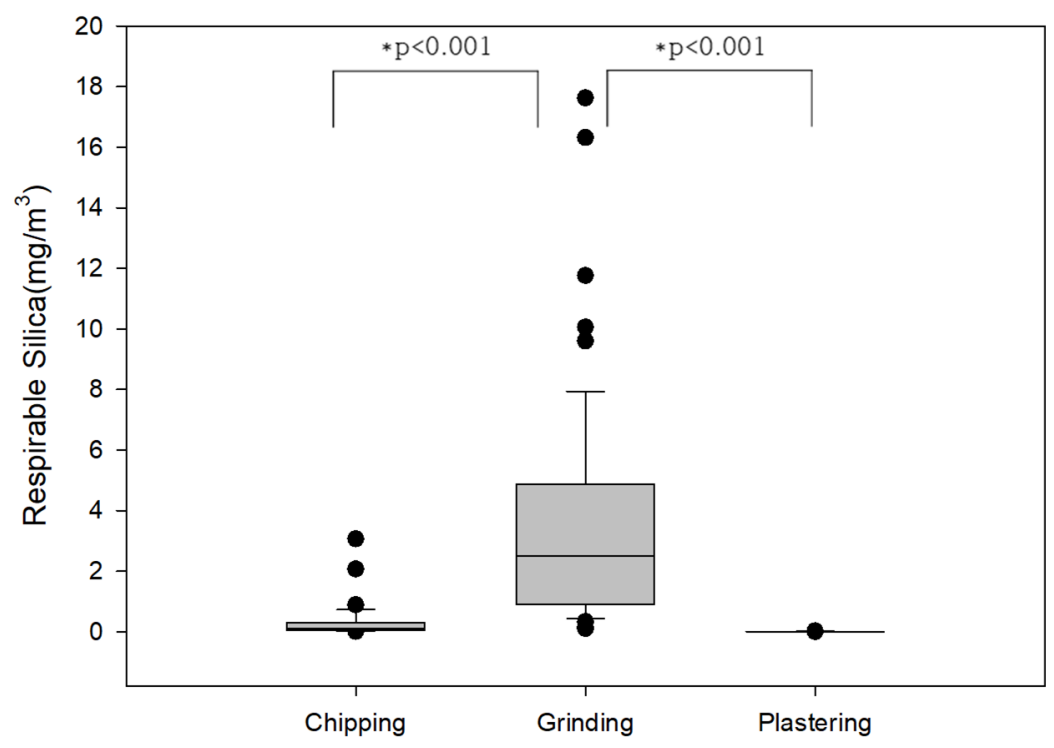

Fig. 2. Respirable crystalline silica exposure concentration by concrete finishing job. The boxes show the $25^{\text {th }}$ and $75^{\text {th }}$ percentiles and whiskers indicate $10^{\text {th }}$ and $90^{\text {th }}$ percentiles. Median is indicated by the line inside the box. Post hoc analysis was conducted by the Scheffe method ( $\mathrm{p}<0.001$; chipping vs. grinding and grinding vs. plastering).

$0.32 \mathrm{mg} \mathrm{m}^{-3}\left(0.002-1.07 \mathrm{mg} \mathrm{m}^{-3}\right)$ for plastering work. All samples exceeded $3 \mathrm{mg} \mathrm{m}^{-3}$ in concrete grinding and $27.7 \%$ (10/36) of the concrete chipping worker samples exceeded $3 \mathrm{mg} \mathrm{m}^{-3}$.

\section{RD and RCS in Concrete Finishing by Type of Working Place}

The concentrations of RD and RCS were significantly different in concrete grinding and plastering work settings $(\mathrm{p}<0.05)$, but not in chipping work settings $(\mathrm{p}>0.5)$. Evaluation of the concentrations of RCS in each concrete grinding working place showed that the GM was highest in a staircase at $4.18 \mathrm{mg} \mathrm{m}^{-3}$ (range: $0.49-17.62 \mathrm{mg} \mathrm{m}^{-3}$ ) (Fig. 3 and Table 3 ). The GM was $2.76 \mathrm{mg} \mathrm{m}^{-3}$ (range: $0.45-$ $7.75 \mathrm{mg} \mathrm{m}^{-3}$ ) inside the apartment units, $1.30 \mathrm{mg} \mathrm{m}^{-3}$ (range: $0.10-5.16 \mathrm{mg} \mathrm{m}^{-3}$ ) in the underground parking lots, and $0.89 \mathrm{mg} \mathrm{m}^{-3}$ (range: $0.14-1.85 \mathrm{mg} \mathrm{m}^{-3}$ ) at the exterior walls. Evaluation of the concentrations of respirable dust at each concrete grinding working place showed that the GM was $95.54 \mathrm{mg} \mathrm{m}^{-3}$ (range: $10.45-367.58 \mathrm{mg} \mathrm{m}^{-3}$ ) in the staircases, $38.73 \mathrm{mg} \mathrm{m}^{-3}$ (range: $5.94-131.2 \mathrm{mg} \mathrm{m}^{-3}$ ) in the apartment units, $39.98 \mathrm{mg} \mathrm{m}^{-3}$ (range: $4.26-250.99 \mathrm{mg} \mathrm{m}^{-3}$ ) in the underground parking lots, and $27.22 \mathrm{mg} \mathrm{m}^{-3}$ (range: 0.10 $5.16 \mathrm{mg} \mathrm{m}^{-3}$ ) at the exterior walls.

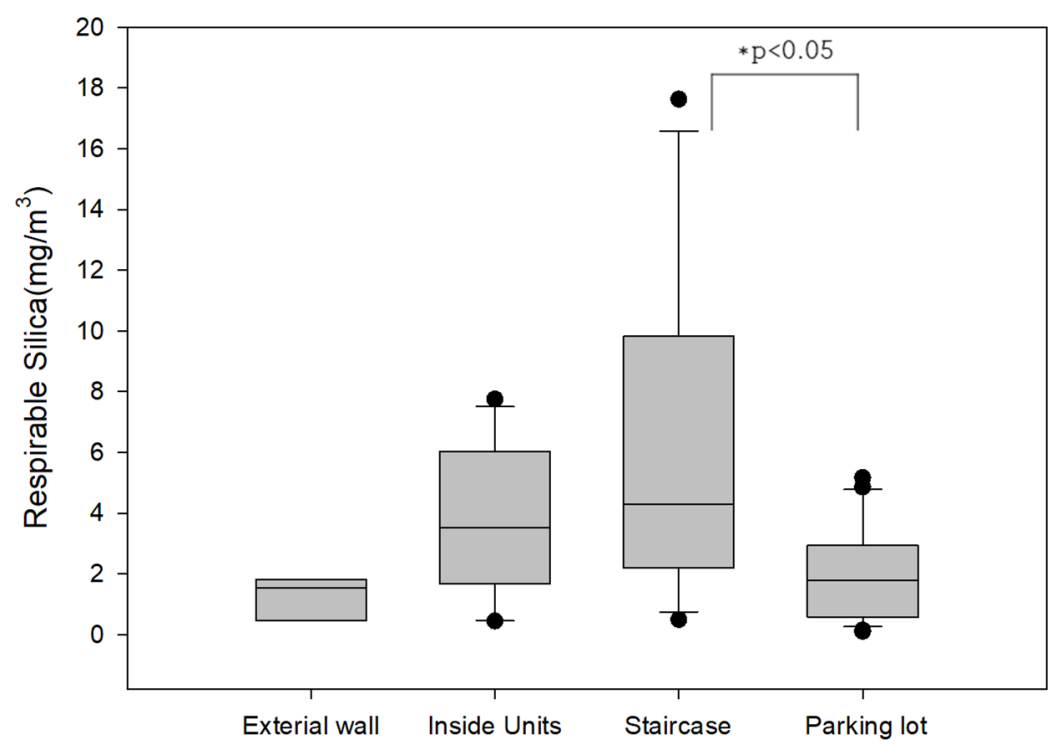

Fig. 3. Respirable crystalline silica exposure concentration of concrete grinding work by working place. The boxes show the $25^{\text {th }}$ and $75^{\text {th }}$ percentiles and whiskers indicate $10^{\text {th }}$ and $90^{\text {th }}$ percentiles. Median is indicated by the line inside the box. Post hoc analysis was conducted by the Scheffe method ( $\mathrm{p}<0.05$; stairway vs. underground). 


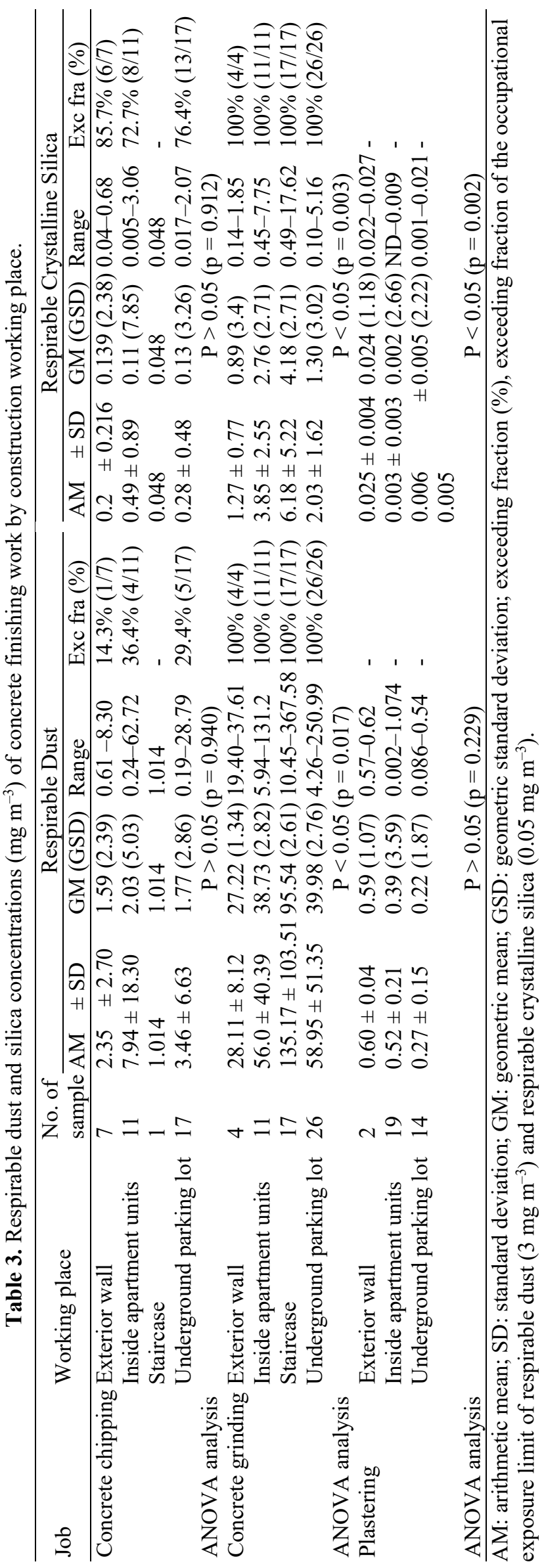

\section{Multiple-regression Analysis of RD and RCS by Job Type, Working Place, and Working Time}

Table 4 summarizes the results of the multiple linear regression analysis of RD and RCS by job type, working place, and working time. The regression model was suitable for satisfying the conditions of Durbin-Watson (which states that the index of auto-correlation should be between 1.8 and 2.2), with indices of 1.778 for RCS and 1.842 for RD. The variation inflation factor (a measure of multicollinearity among independent variables which should be $<10$ ) was between 1.545 and 3.082. As a result, the relative influence of the independent variables in terms of the beta coefficient was the highest for concrete grinding $(\beta=0.990, p<0.001)$, followed by concrete chipping $(\beta=0.516, \mathrm{p}<0.001)$. Neither the type of working place nor working time significantly affected the RD and RCS concentrations.

\section{Correlation between Dust and Silica Concentration by Job Type}

Evaluation of the proportion of crystalline silica in the dust from each job type showed that the crystalline silica content was higher for concrete chipping work. The crystalline silica content was $6.92 \%$ in chipping, $4.12 \%$ in grinding, and $0.94 \%$ in plastering work (Table 5). The correlation coefficients between RCS and RD were $0.970(\mathrm{p}<0.01)$ for chipping, $0.793(\mathrm{p}<0.01)$ for grinding, and $0.100(\mathrm{p}=0.568)$ for plastering work (Figs. 4 and 5).

\section{Size Distribution of Particles from Concrete Finishing}

The mass fraction of inhalable, thoracic, and respirable dust from concrete chipping at the construction sites was $67.4 \%, 23.0 \%$, and $6.5 \%$, respectively, and was $68.7 \%, 26.6 \%$, and $7.9 \%$, from concrete grinding, respectively. The mass fraction of inhalable, thoracic, and respirable crystalline silica from concrete chipping was $73.9 \%, 40.2 \%$, and $17.9 \%$, and $76.0 \%, 46.3 \%$, and $19.7 \%$ from concrete grinding, respectively (Table 6). A cumulative graph of the weights of dust collected from each stage was plotted from the stage with the smallest particle size $(\leq 0.52 \mu \mathrm{m})$ in order to draw a trend line and determine the median diameter of the mass using an effective diameter limit corresponding to $50 \%$ cumulative probability. The result indicated that the median mass diameter of dust was $11.51 \mu \mathrm{m}$ for concrete chipping and $11.05 \mu \mathrm{m}$ for concrete grinding (Fig. 6(a) and Table S3). The results indicated that the median mass diameter of respirable crystalline silica was $9.59 \mu \mathrm{m}$ for concrete chipping and $8.86 \mu \mathrm{m}$ for concrete grinding (Fig. 6(b) and Table S3). Considering the proportion of crystalline silica in the dust from each stage, the crystalline silica content was higher in the dust with smaller particle sizes. The content was particularly high in Stage 6 (range: $1.55-3.5 \mu \mathrm{m}$ ) and Stage 8 (range: $0.52-0.93 \mu \mathrm{m})$ (Table 7).

\section{Discussion}

The RD and RCS concentrations present during concrete chipping, grinding, and plastering work was evaluated at eight apartment complex construction sites. All the RCS samples from concrete grinding work and $75 \%$ of the RCS samples from chipping work exceeded the KOEL $\left(0.05 \mathrm{mg} \mathrm{m}^{-3}\right)$. The 
Table 4. Multiple regression analysis of RD and RCS by job type and working place. (Reference: job [plastering], working place [exterior wall], company [h])

\begin{tabular}{|c|c|c|c|c|}
\hline & \multicolumn{2}{|c|}{$R C S$} & \multicolumn{2}{|c|}{$R D$} \\
\hline & $\mathrm{B}$ & $\beta$ & $\mathrm{B}$ & $\beta$ \\
\hline Intercept & -4.653 & & -0.720 & \\
\hline Job (grinding) & 5.766 & $0.990 * * *$ & 4.571 & $0.970 * * *$ \\
\hline Job (chipping) & 3.332 & $0.516 * * *$ & 1.531 & $0.293 * * *$ \\
\hline Working place (staircase) & 0.536 & 0.064 & 0.810 & $0.120^{*}$ \\
\hline Working place (inside apartment unit) & -0.272 & -0.044 & 0.294 & 0.058 \\
\hline Working place (underground parking lot) & -0.256 & -0.044 & -0.046 & -0.010 \\
\hline Sampling time & -0.002 & -0.083 & -0.001 & -0.057 \\
\hline Adjusted $\mathrm{R}^{2}$ & 0.841 & & 0.842 & \\
\hline Durbin-Watson & 1.778 & & 1.824 & \\
\hline $\mathrm{F}$ & 107.338 & & 108.147 & \\
\hline
\end{tabular}

$* \mathrm{p}<0.05, * * * \mathrm{p}<0.001$.

RD: respirable dust; RCS: respirable crystalline silica.

Table 5. Crystalline silica proportion (\%) of sampled dust in each job type.

\begin{tabular}{|c|c|c|c|c|}
\hline \multirow{2}{*}{ Job } & \multirow{2}{*}{$\mathrm{n}$} & \multicolumn{2}{|c|}{ Crystalline silica proportion $(\%)$} & \multirow{2}{*}{$\begin{array}{l}\text { Correlation } \mathrm{b} / \mathrm{w} \text { silica and dust } \\
\text { (Pearson correlation factor) }\end{array}$} \\
\hline & & $\mathrm{AM} \pm \mathrm{SD}$ & GM (GSD) & \\
\hline Concrete chipping & 36 & $8.00 \pm 3.80$ & $6.92(1.81)$ & $0.970^{*}$ \\
\hline Concrete grinding & 58 & $5.00 \pm 2.72$ & $4.12(2.03)$ & $0.793 *$ \\
\hline Plastering & 35 & $1.70 \pm 1.71$ & $0.94(3.52)$ & 0.100 \\
\hline Total & 129 & $4.94 \pm 3.68$ & $3.19(3.19)$ & $0.864 *$ \\
\hline
\end{tabular}

$* \mathrm{p}<0.01$.

AM: arithmetic mean; SD: standard deviation; GM: geometric mean; GSD: geometric standard deviation.

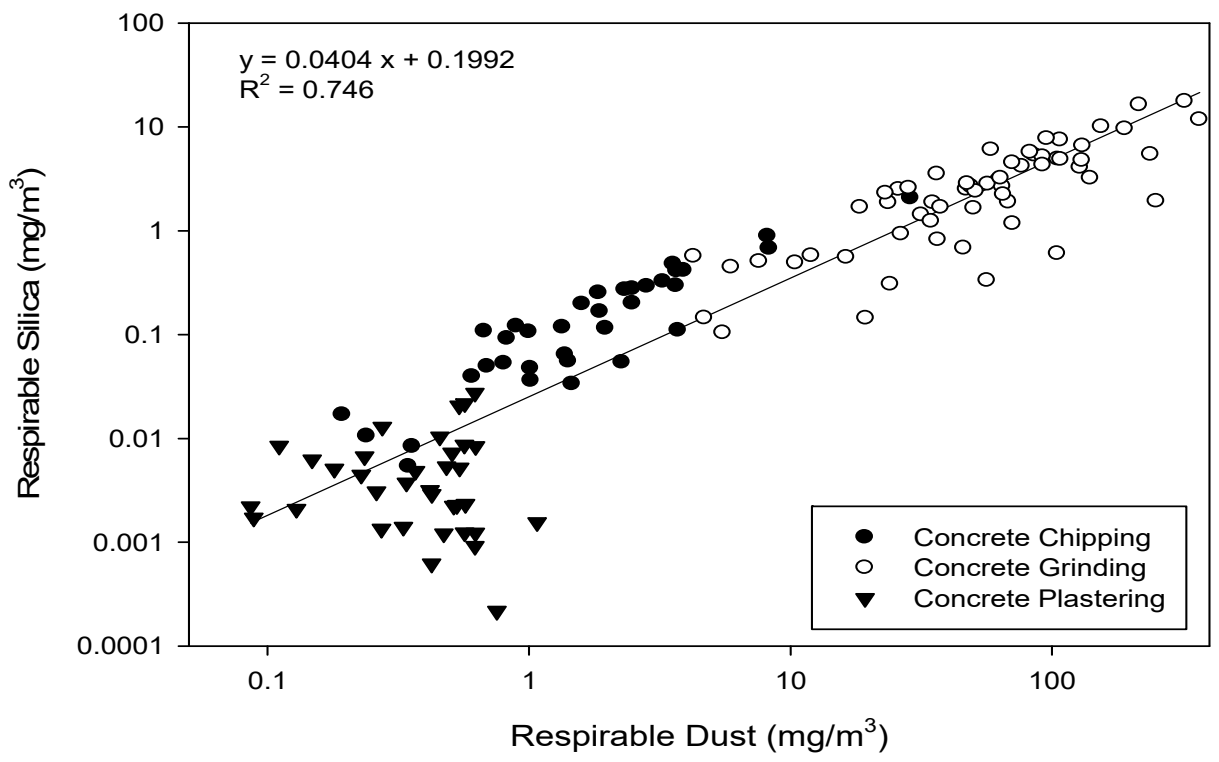

Fig. 4. Respirable dust and silica concentration by concrete finishing job type.

GM of RCS concentrations was highest in concrete grinding (2.06 $\left.\mathrm{mg} \mathrm{m}^{-3}\right)$, followed by concrete chipping $\left(0.12 \mathrm{mg} \mathrm{m}^{-3}\right)$ and plastering work $\left(0.003 \mathrm{mg} \mathrm{m}^{-3}\right)$. The GM of RCS concentrations present during concrete grinding work differed by the type of working place, with the highest concentration of RCS in staircases $\left(4.18 \mathrm{mg} \mathrm{m}^{-3}\right)$, followed by the inside walls of apartment units $\left(2.76 \mathrm{mg} \mathrm{m}^{-3}\right)$, underground parking lots $\left(1.30 \mathrm{mg} \mathrm{m}^{-3}\right)$, and exterior walls $\left(0.89 \mathrm{mg} \mathrm{m}^{-3}\right)$.
Furthermore, the concentration was statistically different according to the type of job. Previous studies have reported (Table S5) GM concentrations of $0.7 \mathrm{mg} \mathrm{m}^{-3}$ and $0.42 \mathrm{mg} \mathrm{m}^{-3}$ for a recess miller (Lumens and Spee, 2001; Tjoe et al., 2003), $0.63 \mathrm{mg} \mathrm{m}^{-3}$ for a surface grinder (Flanagan et al., 2003), $0.07 \mathrm{mg} \mathrm{m}^{-3}$ for a concrete floor sander (Flanagan et al., 2003), and $1.28 \mathrm{mg} \mathrm{m}^{-3}$ (median value) for a painter blaster (Rappaport et al., 2003). In this study, the GM of RCS was 


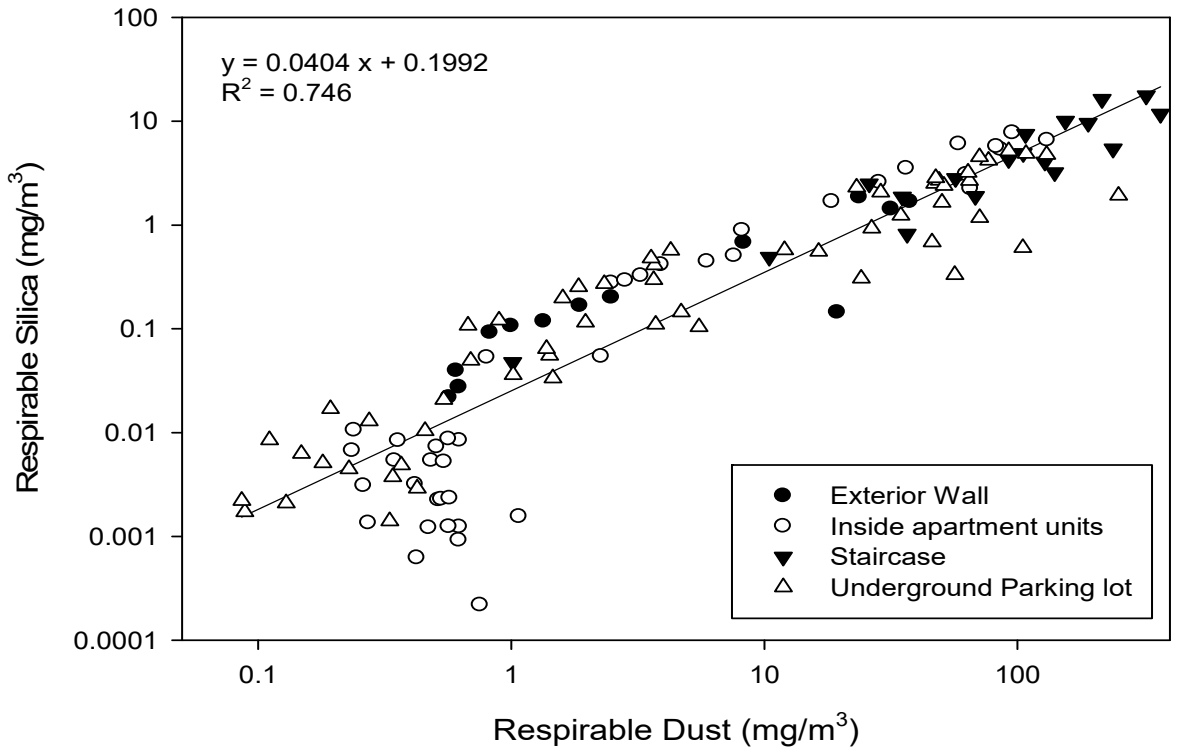

Fig. 5. Respirable dust and silica concentration by working place type.

Table 6. ACGIH particle size-selective fraction (\%) of eight-stage cascade impactors in concrete chipping and grinding work.

\begin{tabular}{llllcc}
\hline \multirow{2}{*}{ Methods } & \multirow{2}{*}{ Job } & \multirow{2}{*}{ ACGIH particle size-selective fraction (\%) } \\
\cline { 4 - 6 } & & Inhalable & Thoracic & Respirable \\
\hline \multirow{2}{*}{ By dust concentration } & Concrete chipping & 3 & 67.4 & 23.0 & 6.5 \\
\cline { 4 - 6 } By silica concentration & Concrete grinding & 3 & 68.7 & 26.6 & 7.9 \\
& Concrete chipping & 3 & 73.9 & 40.2 & 17.9 \\
\cline { 4 - 6 } & Concrete grinding & 3 & 76.0 & 46.3 & 19.7
\end{tabular}

Tables S1-S2 present the summary of raw data.

much higher than that reported in previous studies. We assume that the reason was due to the unique housing style of Korea, which consists of large-scale apartment complexes made of concrete and each apartment unit consists of several small rooms. Specifically, in concrete grinding work, where a concrete face is polished by more than $10,000 \mathrm{rpm}$ (revolutions per minute) using an industrial diamond wheel, much higher concentrations of RCS are generated compared to chipping and plastering.

The concrete-dust control methods utilized so far include covering the grinding wheel with a ventilation cap and connecting it to a vacuum dust collector (Akbar-Khanzadeh et al., 2007; Meeker et al., 2009; Akbar-Khanzadeh et al., 2010), the wet method (Beamer et al., 2005; Meeker et al., 2009; Healy et al., 2014), and wearing respirators.

Akbar-Khanzadel et al. (2010) reported that the concentration of RCS measured during concrete grinding was highly affected by the efficiency of ventilation, the diameter of the grinder, and the use of local exhaust ventilation (LEV) systems. The study reported that general ventilation was $66 \%$ efficient in controlling RCS, LEV systems were $98-99 \%$ efficient, and wet grinding was $94 \%$ efficient. Healy et al. (2014) also compared the concentrations of RCS measured during the use of four types of concrete grinder covers currently used at construction sites. The concentrations of RD and RCS were significantly lower when a cover was used compared to when no cover was used. The concentration of RD was $7.1 \mathrm{mg} \mathrm{m}^{-3}$ when no cover was used but was reduced by about $92 \%$ to $0.5 \mathrm{mg} \mathrm{m}^{-3}$ when a cover was used.

Beamer et al. (2005) applied various wet engineering methods to reduce the concentration of RCS from brick chipping and concluded that the moisture mist method was highly efficient and suitable for application at construction sites. Moreover, the moisture dries rapidly on the sprayed surface, preventing slipping and falling on wet surfaces in the working place.

Although the LEV systems and the wet method showed significant reductions in concentrations and workers wore half-mask respirators, some workers were still overexposed to RCS (Middaugh et al., 2012). In the construction of largescale apartment complexes, the GM of RCS was over $2 \mathrm{mg} \mathrm{m}^{-3}$ and, even though the reduction efficiency was $95 \%$, the reduced concentration was still $0.1 \mathrm{mg} \mathrm{m}^{-3}$, which exceeds the KOEL of $0.05 \mathrm{mg} \mathrm{m}^{-3}$. Furthermore, the concentration resulting from reduction efficiencies of $99 \%$ was still $0.02 \mathrm{mg} \mathrm{m}^{-3}$, which is almost the same as the ACGIH TLV of $0.025 \mathrm{mg} \mathrm{m}^{-3}$.

In the case of concrete grinding work in staircases, the concentration was $4.18 \mathrm{mg} \mathrm{m}^{-3}$ and even if $99 \%$ of the RCS concentration was reduced, it would still exceed the KOEL. This means a single engineering control, such as LEV systems 
(a)

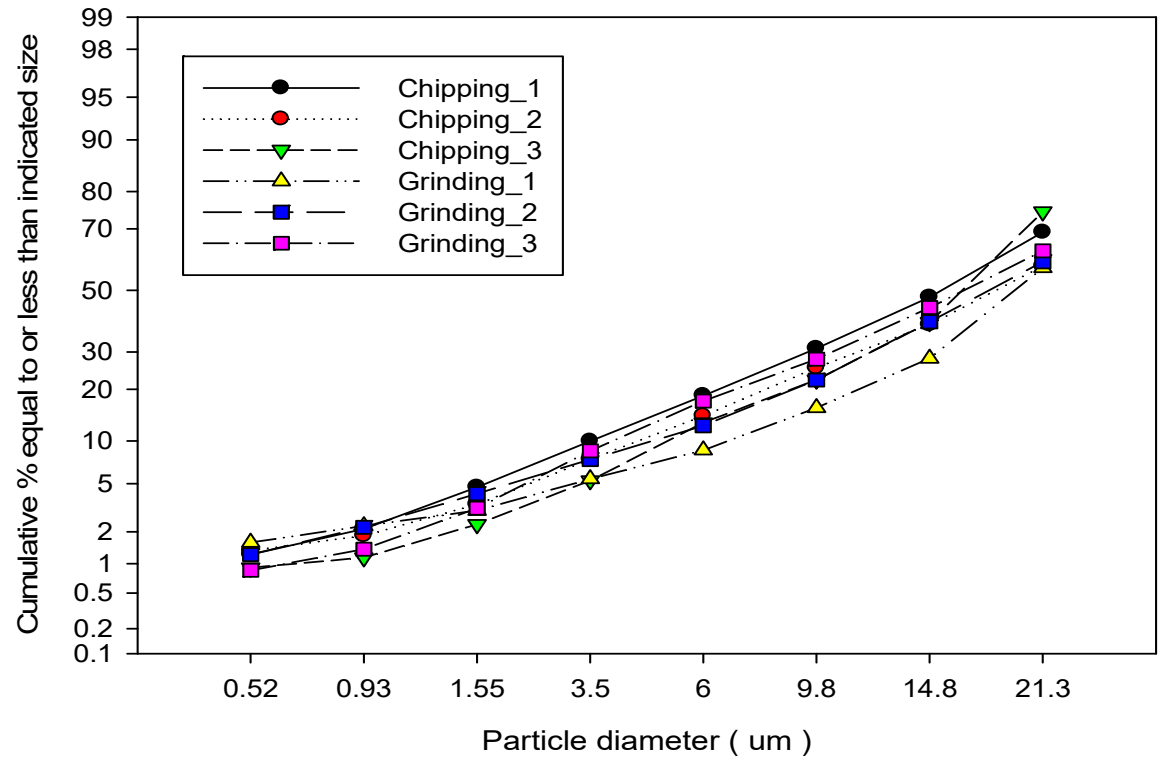

(b)

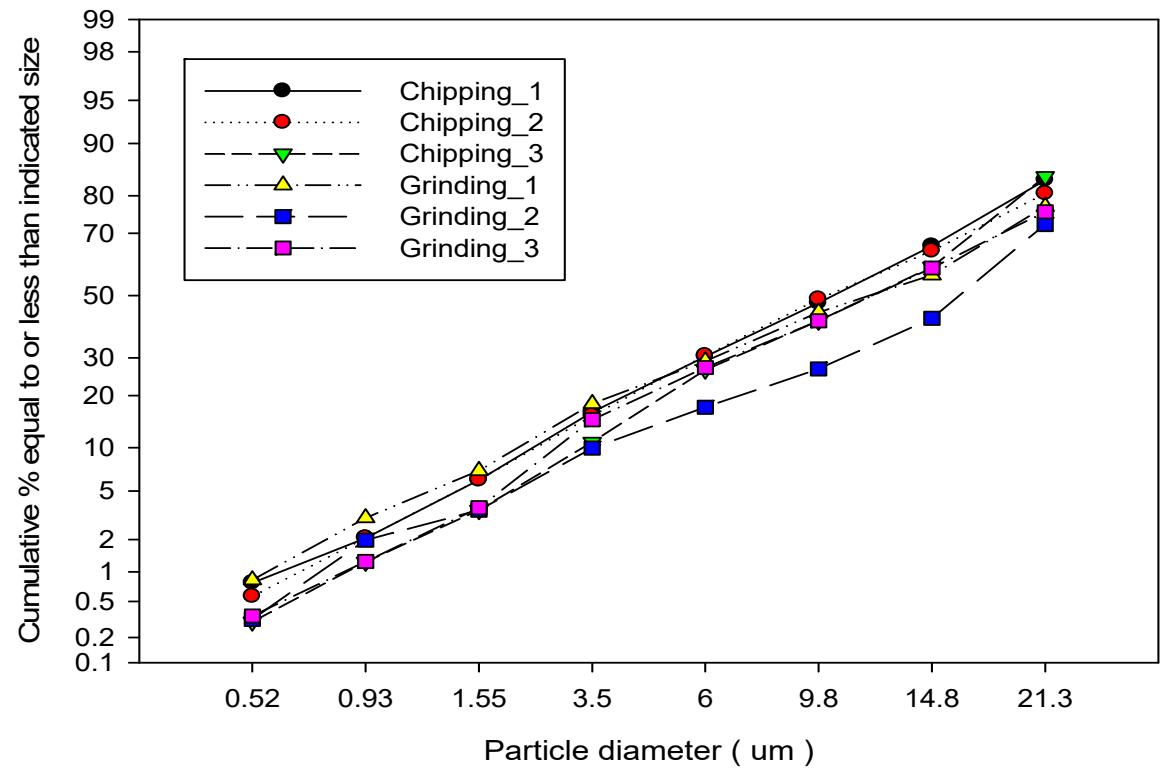

Fig. 6. Size distribution of respirable dust and respirable crystalline silica in concrete chipping and grinding: (a) respirable dust and (b) respirable crystalline silica. Table S3 presents the summary of raw data.

Table 7. Crystalline silica proportion (\%) of sampled dust in each impactor stage.

\begin{tabular}{|c|c|c|c|c|c|}
\hline \multirow{3}{*}{$\begin{array}{l}\text { Stage } \\
\text { No. }\end{array}$} & \multirow{3}{*}{$\begin{array}{l}\text { Cut-point diameter } \\
(\mu \mathrm{m})\end{array}$} & \multicolumn{4}{|c|}{ Crystalline silica proportion (\%) of sampled dust } \\
\hline & & \multicolumn{2}{|c|}{ Concrete chipping } & \multicolumn{2}{|c|}{ Concrete grinding } \\
\hline & & $\mathrm{n}$ & Mean \pm SD & $\mathrm{n}$ & Mean \pm SD \\
\hline 1 & 21.3 & 3 & $1.74 \pm 0.69$ & 3 & $1.32 \pm 0.11$ \\
\hline 2 & 14.8 & 3 & $3.04 \pm 2.20$ & 3 & $1.90 \pm 0.32$ \\
\hline 3 & 9.8 & 3 & $2.72 \pm 0.59$ & 3 & $2.79 \pm 0.40$ \\
\hline 4 & 6 & 3 & $3.89 \pm 1.19$ & 3 & $3.75 \pm 0.33$ \\
\hline 5 & 3.5 & 3 & $5.57 \pm 2.55$ & 3 & $4.81 \pm 0.75$ \\
\hline 6 & 1.55 & 3 & $7.65 \pm 3.54$ & 3 & $5.51 \pm 0.43$ \\
\hline 7 & 0.93 & 3 & $5.93 \pm 5.24$ & 3 & $4.90 \pm 1.28$ \\
\hline 8 & 0.52 & 3 & $6.15 \pm 2.37$ & 3 & $6.74 \pm 2.67$ \\
\hline B & Backup filter & 3 & $1.03 \pm 0.21$ & 3 & $1.16 \pm 0.47$ \\
\hline
\end{tabular}

SD: standard deviation.

Table S4 presents the summary of raw data. 
or respirators, cannot reduce RCS enough to meet acceptable exposure criteria. During concrete grinding work, multiple methods must be used to improve the work environment and reduce RCS concentrations. The following are ways to improve the work environment: using an LEV system or wet method simultaneously with high-efficiency respirators, reducing the total working time, and using full-faced air-purifying respirators. In this study, the MMAD of concrete chipping and grinding work was about 10-12 $\mu \mathrm{m}$, which was much smaller than the MMAD of concrete cutting dust at $27.5 \mu \mathrm{m}$ (Shepherd et al., 2009). Particle size may also vary depending on the type of work tool used. For example, high-speed grinding with a diamond wheel may produce smaller particle sizes than that from cutting. However, all grinding, chipping, and cutting tasks involve mechanical actions and the MMAD of dust is larger than that of welding fumes, diesel exhaust, or smoke. Understanding the characteristics of the particle-size distribution of dust is important for reducing exposure. However, information on the particle size of silica containing dust at construction sites is very limited (Shepherd et al., 2009). Further studies of dust-minimization methods based on particle-size distribution should be conducted.

\section{CONCLUSIONS}

Concrete finishing workers at apartment complex construction sites are exposed to unacceptably high concentrations of RD and RCS. Even if engineering controls, such as LEV systems, wet methods, and highly efficient respirators are applied, the RD and RCS may still exceed occupational exposure limits. To protect workers' health, dust-minimizing construction methods as well as highefficiency respirators paired with local exhaust ventilation systems or wet methods must be employed. Further efforts to reduce the total working time and to use full-faced airpurifying respirators are required.

\section{SUPPLEMENTARY MATERIAL}

Supplementary data associated with this article can be found in the online version at http://www.aaqr.org.

\section{REFERENCES}

Akbar-Khanzadeh, F. and Brillhart, R.L. (2002). Respirable crystalline silica dust exposure during concrete finishing (grinding) using hand-held grinders in the construction industry. Ann. Occup. Hyg. 46: 341-346.

Akbar-Khanzadeh, F., Milz, S., Ames, A., Susi, P.P., Bisesi, M., Khuder, S.A. and Akbar-Khanzadeh, M. (2007). Crystalline silica dust and respirable particulate matter during indoor concrete grinding - wet grinding and ventilated grinding compared with uncontrolled conventional grinding. J. Occup. Environ. Hyg. 4: 770 779.

Akbar-Khanzadeh, F., Milz, S.A., Wagner, C.D., Bisesi, M.S., Ames, A.L., Khuder, S., Susi, P. and Akbar-Khanzadeh, M. (2010). Effectiveness of dust control methods for crystalline silica and respirable suspended particulate matter exposure during manual concrete surface grinding. J. Occup. Environ. Hyg. 7: 700-711.

American Conference of Governmental Industrial Hygienists (ACGIH) (2013). Threshold limit values for chemical substances and physical agents and biological exposures indices. ACGIH. Appendix C; pp. 80-83

Anderson Samplers, Inc. (1982). Instruction Mannual Series 290 Marple Personal Impactors. Bulletin \#290 I.M-3-82

Beamer, B.R., Shulman, S., Maynard, A., Williams, D. and Watkins, D. (2005). Evaluation of misting controls to reduce respirable silica exposure for brick cutting. Ann. Occup. Hyg. 49: 503-510.

Beaudry, C., Lavoué, J., Sauvé, J.F., Bégin, D., Dion, C. and Rhazi, M.S. (2013). Occupational exposure to silica in construction workers: A literature-based exposure database. J. Occup. Environ. Hyg. 10: 71-77.

Bello, D., Virji, M.A., Kalil, A.J. and Woskie, S.R. (2002). Quantification of respirable, thoracic, and inhalable quartz exposures by FT-IR in personal impactor samples from construction sites. Appl. Occup. Environ. Hyg. 17: 580-90.

Flanagan, M.E., Seixas, N., Majar, M., Camp, J. and Morgan, M. (2003). Silica dust exposures during selected construction activities. AIHA J. 64: 319-328.

Healy, C.B., Coggins, M.A., Van Tongeren, M., MacCalman, L. and McGowan, P. (2014). An evaluation of on-tool shrouds for controlling respirable crystalline silica in restoration stone work. Ann. Occup. Hyg. 58: 1155-1167

International Agency for research on Cancer (IARC) (2012). Silica dust, crystalline, in the form of quartz or cristobalite. In IARC monographs on the evaluation of carcinogenic risks to humans, Volume 100C. World Health Organization, Lyon, France, p. 355-405.

Lumens, M.E. and Spee, T. (2001). Determinants of exposure to respirable quartz dust in the construction industry. Ann. Occup. Hyg. 45: 585-595.

Meeker, J.D., Cooper, M.R., Lefkowitz, D. and Susi, P. (2009). Engineering control technologies to reduce occupational silica exposures in masonry cutting and tuckpointing. Public Health Rep. 124: 101-111.

Middaugh, B., Hubbard, B., Zimmerman, N. and McGlothlin, J. (2012). Evaluation of cut-off saw exposure control methods for respirable dust and crystalline silica in roadway construction. J. Occup. Environ. Hyg. 9: 157-165.

NIOSH hazards review (2002). IOSH hazards review: Health effects of occupational exposure to respirable crystalline silica. Department of Health and Human Services, Centers for Disease Control and Prevention, National Institute for Occupational Safety and Health, NIOSH Publication, Cincinnati, OH, No. 2002-129.

NIOSH (2003). Silica, Crystalline by IR: Method 76 02, issue 3, 15 March 2003, https://www.cdc.gov/ni osh/docs/2003-154/pdfs/7602.pdf

Oude, H.K., van Deurssen, E., Meijster, T., Tielemans, E., Heederik, D. and Pronk, A. (2014). 'Relieved Working' study: systematic development and design of an intervention to decrease occupational quartz exposure at construction worksites. BMC Public Health 14: 760-771. Rappaport, S.M., Goldberg, M., Susi, P. and Herrick, R.F. 
(2003). Excessive exposure to silica in the US construction industry. Ann. Occup. Hyg. 47: 111-122.

Rushton, L., Hutchings, S. and Brown, T. (2008). The burden of cancer at work: Eatimation as the first step to prevention. Occup. Environ. Med. 65: 789-800.

Sauvé, J.F., Beaudry, C., Bégin, D., Dion, C., Gérin, M. and Lavoué, J. (2013). Silica exposure during construction activities: Statistical modeling of task-based measurements from the literature. Ann. Occup. Hyg. 57: 432-438.

Sauvé, J.F. (2015). Historical and emerging workplaces affected by silica exposure since the 1930 Johannesburg conference on Silicosis, with special reference to construction. Am. J. Ind. Med. 58: S67-S71.

Shepherd, S., Woskie, S.R., Holcroft, C. and Ellenbecker. M. (2009). Reducing silica and dust exposures in construction during use of powered concrete-cutting hand tools: Efficacy of local exhaust ventilation on hammer drills. J. Occup. Environ. Hyg. 6: 42-51.

Tjoe Nij, E., Hilhorst, S., Spee, T., Spierings, J., Steffens, F., Lumens, M. and Heederik, D. (2003). Dust control measures in the construction industry. Ann. Occup. Hyg. 47: 211-218.

Vaughan, N.P. (1989). The Andersen impactor: Calibration, wall losses and numerical simulation. J. Aerosol Sci. 20: 67-90.

Received for review, June 27, 2019

Revised, August 21, 2019 Accepted, September 3, 2019 